\title{
Effects of a ketogenic diet on body composition and strength in trained women
}

Salvador Vargas-Molina ${ }^{1,2} \mathbb{D}$, Jorge L. Petro ${ }^{3,4} \mathbb{D}$, Ramón Romance ${ }^{1}$, Richard B. Kreider ${ }^{5}$, Brad J. Schoenfeld ${ }^{6}$, Diego A. Bonilla ${ }^{4}$ (D) and Javier Benítez-Porres ${ }^{1 *}$ (D)

\begin{abstract}
Background: The effect of ketogenic diets (KD) on body composition in different populations has been investigated. More recently, some have recommended that athletes adhere to ketogenic diets in order to optimize changes in body composition during training. However, there is less evidence related to trained women. We aimed to evaluate the effect of a KD on body composition and strength in trained women following an eight-week resistance training (RT) program.

Methods: Twenty-one strength-trained women ( $27.6 \pm 4.0$ years; $162.1 \pm 6.6 \mathrm{~cm} ; 62.3 \pm 7.8 \mathrm{~kg} ; 23.7 \pm 2.9 \mathrm{~kg} \cdot \mathrm{m}^{-2}$ ) were randomly assigned to either a non-KD group $(n=11, \mathrm{NKD})$ or a KD group $(n=10, \mathrm{KD})$. Study outcomes included body composition as measured by dual-energy X-ray absorptiometry (DXA), strength levels measured using one maximum repetition (RM) in back squat and bench press (BP), and countermovement jump (CMJ) measured on a force plate.
\end{abstract}

Results: A significant reduction in fat mass was observed in $\operatorname{KD}(-1.1 \pm 1.5 \mathrm{~kg} ; P=0.042 ; d=-0.2)$ but not in $\operatorname{NDK}(0.3 \pm 0.8 \mathrm{~kg} ; P=0.225 ; d=0.1)$. No significant changes in fat-free mass were observed in $\mathrm{KD}(-0.7 \pm 1.7$ $\mathrm{kg} ; P=0.202 ; d=-0.1)$ or NKD $(0.7 \pm 1.1 \mathrm{~kg} ; P=0.074 ; d=0.2)$, but absolute changes favored NKD. No significant changes in BP were observed in $\mathrm{KD}(1.5 \pm 4.6 \mathrm{~kg} ; P=0.329 ; d=0.2)$, although significant changes were noted in the squat and CMJ $(5.6 \pm 7.6 \mathrm{~kg} ; P=0.045 ; d=0.5$ and $1.7 \pm 1.9 \mathrm{~cm} ; P=0.022 ; d=0.6$, respectively). In contrast, NKD showed significant increases in BP $(4.8 \pm 1.8 ; P<0.01 ; d=0.7)$, squat $(15.6 \pm 5.4$ $\mathrm{kg} ; P=0.005 ; d=1.4)$ and $\mathrm{CMJ}(2.2 \pm 1.7 \mathrm{~cm} ; P=0.001 ; d=0.5)$.

Conclusions: Findings indicate that a KD may help to decrease fat mass and maintain fat-free mass after eight 8 weeks of RT in trained-women but is suboptimal for increasing fat-free mass.

Keywords: Resistance training, Female, High-fat diet, Energy intake, Fat distribution

\footnotetext{
*Correspondence: benitez@uma.es

'Human Kinetics and Body Composition Laboratory, University of Málaga, Bulevar Louis Pasteur, 25, 29010 Málaga, Spain

Full list of author information is available at the end of the article
}

(c) The Author(s). 2020 Open Access This article is licensed under a Creative Commons Attribution 4.0 International License, which permits use, sharing, adaptation, distribution and reproduction in any medium or format, as long as you give appropriate credit to the original author(s) and the source, provide a link to the Creative Commons licence, and indicate if changes were made. The images or other third party material in this article are included in the article's Creative Commons licence, unless indicated otherwise in a credit line to the material. If material is not included in the article's Creative Commons licence and your intended use is not permitted by statutory regulation or exceeds the permitted use, you will need to obtain permission directly from the copyright holder. To view a copy of this licence, visit http://creativecommons.org/licenses/by/4.0/ The Creative Commons Public Domain Dedication waiver (http://creativecommons.org/publicdomain/zero/1.0/) applies to the data made available in this article, unless otherwise stated in a credit line to the data. 


\section{Introduction}

Dietary manipulation is an essential component for optimizing the adaptation to physical exercise; therefore, modulating the intake of certain specific nutrients, as is the case with a ketogenic diet (KD), can influence the ability to achieve physical objectives [1]. A KD is based on a marked reduction in carbohydrate consumption (i.e., $\approx 50 \mathrm{~g}$ per day or $10 \%$ of total daily caloric intake) and a corresponding increase in dietary fat $(\approx 60-80 \%$ of total calories) and protein consumption (i.e., $\approx 1.2-1.5$ $\left.\mathrm{g} \cdot \mathrm{kg}^{-1} \cdot \mathrm{d}^{-1}\right)$ [2], although protein intake should be even higher during a strength-based training program. This macronutrient distribution leads to an increase in the production of ketone bodies (KB), such as acetoacetate, $\beta$-hydroxybutyrate and acetone, and consequently to the state of physiological ketosis (i.e., KB blood levels between 7 and $8 \mathrm{mM}$ and blood $\mathrm{pH}$ of $\approx 7.4$ ) [3]. The increase in $\mathrm{KB}$ and the subsequent physiological adaptations after following a KD not only have shown positive effects in the reduction of body mass (BM) in obese subjects [4], but also the reduction in blood concentrations of low-density lipoprotein cholesterol, triacylglycerols and glucose while an increase in high-density lipoprotein cholesterol has been reported [5]. Similarly, there is evidence of the benefits of KDs in the treatment or management of neurological diseases such as epilepsy [6-9] and certain types of cancer [10-12]. Therefore, adherence to a KD can be considered part of the therapeutic management of these pathologies.

In the context of physical performance, it can be speculated that KDs do not produce better results than carbohydrate-rich diets, although they could have limited benefits or, at least, not harmful to performance under certain scenarios [13]. Thus, a KD conceivably may be a plausible nutritional strategy in specific scenarios, such as: i) during prolonged low-intensity events predominantly reliant on fat oxidation to fuel exercise; ii) during the pre-competition carbohydrate-restriction phase prior to bodybuilding and/or physique competitions when it is advantageous to restrict carbohydrate intake; and/or iii) for individuals who prefer to lowcarbohydrate diets [14]. However, recent studies indicate that adherence to KD may impair training adaptations and require additional study $[15,16]$.

Compared to endurance training, few studies have specifically investigated the effects of a $\mathrm{KD}$ on body composition and strength levels in resistance-trained subjects undertaking a resistance training (RT) program. It was previously reported that an eight-week RT program accompanied by a KD reduced fat mass (FM) and preserved fat-free mass (FFM) in trained men [17]. Similarly, other studies have shown favorable changes in body composition ( $\uparrow$ FFM and $\downarrow$ FM), strength and total testosterone [18]. However, these investigations have been conducted in men. Research investigating the effects of a KD on changes in body composition and cardiovascular risk markers are even less in women, and generally performed with no RT component and with obese and untrained female population [19, 20]. For instance, Jabekk et al. [21] reported positive changes in body composition (FM reduction and preservation of FFM) during a KD intervention in conjunction with RT in overweight women. Gregory et al. [22] also showed reductions in FM while FFM was maintained during a cross-training program in non-elite trained individuals (mostly women). Even though many studies on RT with different nutritional interventions (including on lowcarbohydrate high-protein diets) have been performed in several women populations [23-28], there are a paucity of studies documenting the combined effects of KD and RT, particularly in resistance-trained women.

In view of the current gaps in the literature, the purpose of the present study was to evaluate the effects of a KD on body composition and strength levels in women undergoing a regimented RT program. We hypothesized that FM would be reduced and/or maintained while FFM and strength levels would be preserved in women undertaking an eight 8-week RT program in conjunction with a KD.

\section{Materials and methods Study design}

This study was conducted as a randomized, parallel arm, controlled, prospective study. The independent variable was nutritional intervention. The primary outcome variables were changes in body composition.

\section{Participants}

Twenty-one women (age $=27.6 \pm 4.0$ years; height $=$ $162.1 \pm 6.6 \mathrm{~cm}$; body mass $=62.3 \pm 7.8 \mathrm{~kg} ; \mathrm{BMI}=23.7 \pm$ $2.9 \mathrm{~kg} \cdot \mathrm{m}^{-2}$ ) with at least 2 years of continuous RT experience volunteered to participate in this study. All participants committed to following the prescribed diet and RT protocols, monitoring during the eight-week study. Participants were informed of the possible risks of the experiment and provided written informed consent. The study was designed in accordance with the ethical guidelines of the World Medical Association Declaration of Helsinki [29]. The investigation was developed in Málaga (Spain). The first evaluation took place on April 2019 and the second measurement on June of the same year.

Participants who self-reported the use of doping agents (e.g., anabolic-androgenic steroids) during the last 2 years or admitted to taking any dietary supplement during the program were excluded from participation. Women with oligomenorrhea or polycystic ovarian syndrome, as well as those not within the required age range of 18 to 35 years, were excluded. Participants were 


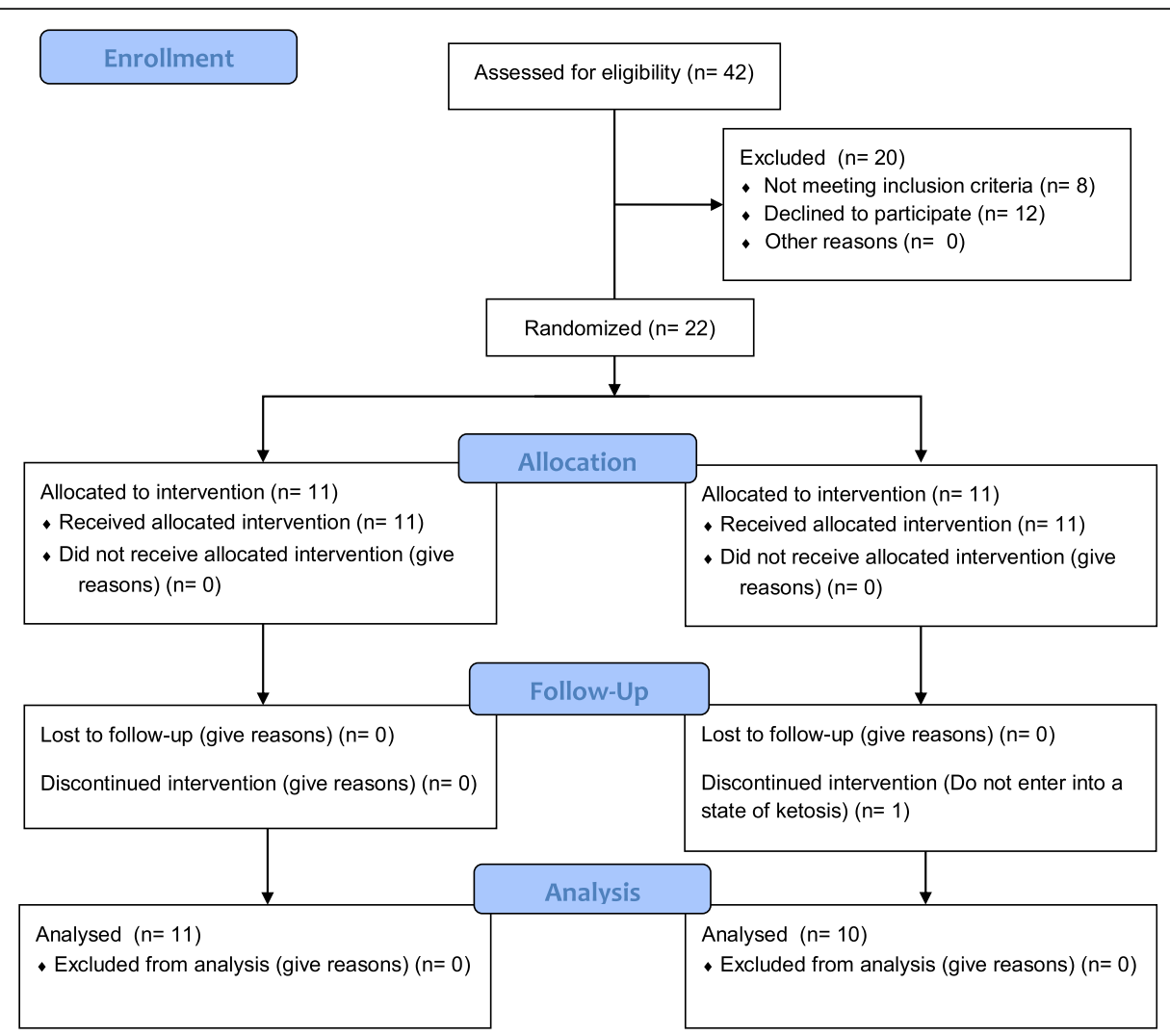

Fig. 1 CONSORT diagram

instructed to avoid performing any structured exercise during the study period other than that prescribed for the intervention. Figure 1 presents a diagram of subject enrollment as per the guidelines of the Consolidated Standards of Reporting Trials (CONSORT).

\section{Procedures}

Participants were randomly assigned to either the KD group $(n=10)$ or the NKD group $(n=11)$, and began their training and diet at the end of the familiarization phase. The research assistants logged all training loads performed by participants for each exercise session. Strength measurements were performed 7 days after menstruation, considering this time would coincide with the follicular phase of the menstrual cycle which has been shown to be correlated to strength increases during RT [30].

\section{Body composition}

Body composition was measured 7 days after menstruation in both the pre- and post-intervention periods to avoid the potential for BM alterations due to water retention caused by hormonal fluctuations [31, 32]. Total body and regional body composition was estimated using dual-energy $\mathrm{x}$-ray absorptiometry (DXA). Each subject was scanned by a certified technician, and the distinguished bone and soft tissue, edge detection, and regional demarcations were calculated by computer algorithms (software version APEX 3.0, Hologic QDR 4500, Bedford, MA). For each scan, participants wore sport clothes and were asked to remove all materials that could attenuate the X-ray beam. This included jewelry items and underwear containing wire. Calibration of the densitometer was checked daily against standard calibration block supplied by the manufacturer (Phantom 21, 965 Lumbar Spine with anthropomorphic characteristics of 4 hydroxyapatite vertebrae included in resin. Coefficient of Variation: $0.415 \%$ ).

The abdominal region was delineated by an upper horizontal border located at half of the distance between the acromion processes and external end of iliac crests, a lower border determined by the external end of iliac crests and the lateral borders extending to the edge of the abdominal soft tissue. All trunk tissue within this standardized height region was selected for analysis. To determine intertester reliability, two different observers manually selected the area for each subject.

\section{Exercise protocol}

The participants initially completed 3 weeks of familiarization to establish training weights for each exercise, followed by an eight-week intervention period. 
Cadence of repetitions was controlled by a metronome (Metronome M1, JSplash Apps). All participants performed the same exercises encompassing the major muscles of the body throughout the duration of the program. The upper limb exercises included bench presses, barbell rows, military presses, lat pulldown, incline chest presses, biceps curls and triceps pushdowns. Lower limb exercises included squats, lunges, leg presses, hip thrusts, leg extensions, lying leg curls and standing calf raises.

After familiarization, participants completed four training sessions per week (divided into 2 4-week cycles) for 8 weeks. An upper/lower body split routine was employed, with a 72-h recovery period between sessions for the same muscle complex. Both groups used a nonlinear periodized workout scheme, with the variables manipulated based on the objective of each phase as follows: strength, hypertrophy and muscular endurance. This sequence was followed by a deload whereby the volume was reduced (series $\mathrm{x}$ repetition $\mathrm{x}$ load) in the last week of each cycle (recovery phase). In total, 2 4week cycles were completed. Figure 2 provides the specific manipulation of variables for each phase of the training cycle.

The loads were adjusted in the hypertrophy and muscular endurance phases starting with the first series of each exercise, and they were modified in subsequent series based on perceived exertion and the number of repetitions completed, to achieve concentric failure in every set and maintain the range of established repetitions. In contrast, during the week focused on strength development, participants were instructed to terminate sets 1-2 repetitions short of failure. All participants increased training loads during the first 3 weeks of each cycle as long as they were able to complete the sets without compromising technical execution.

Training sessions were monitored by RT specialists, adjusting the loads whenever necessary. The lifted loads and perceived exertion in each exercise were monitored by the strength and conditioning specialist using a paper tracking form throughout the experiment. All participants used the same exercises for the duration of the program.

\section{Nutrition intervention}

Diet planning was based on the participants' FFM (g.kg$\mathrm{FFM}^{-1} \cdot \mathrm{d}^{-1}$ ) considering that they were trained subjects, did not have excess of body fat and that FFM was obtained through a valid method such as DXA. To avoid low energy availability and consequent changes in the menstrual cycle, the participants energy intake was set at $\approx 40-45 \mathrm{kcal} \cdot \mathrm{kg}-\mathrm{FFM}^{-1} \cdot \mathrm{d}^{-1}$, which is higher than that reported in previous studies ( $30 \mathrm{kcal} \cdot \mathrm{kg}^{-1}$ lean body mass) $[34,35]$.

In the KD group, participants were instructed to consume $30-40 \mathrm{~g} \cdot \mathrm{d}^{-1}$ of carbohydrates $(\approx 20 \mathrm{~g}$ of dietary fiber) with a protein intake higher than the current recommendation of $1.7 \mathrm{~g} \cdot \mathrm{kg}^{-1} \cdot \mathrm{d}^{-1}$ [36]. The remaining calories were obtained in the form of dietary fats $(\approx 31 \%$ saturated; $\approx 40 \%$ monounsaturated; $\approx 29 \%$ polyunsaturated fat). Participants were advised to eat 3-6 meals a day. To assess dietary compliance, urinary ketones concentrations were measured weekly in the early morning using over-the-counter reagent strips (Ketostix, Bayer Vital GmbH, Leverkusen, Germany) [37]. Alternatively,

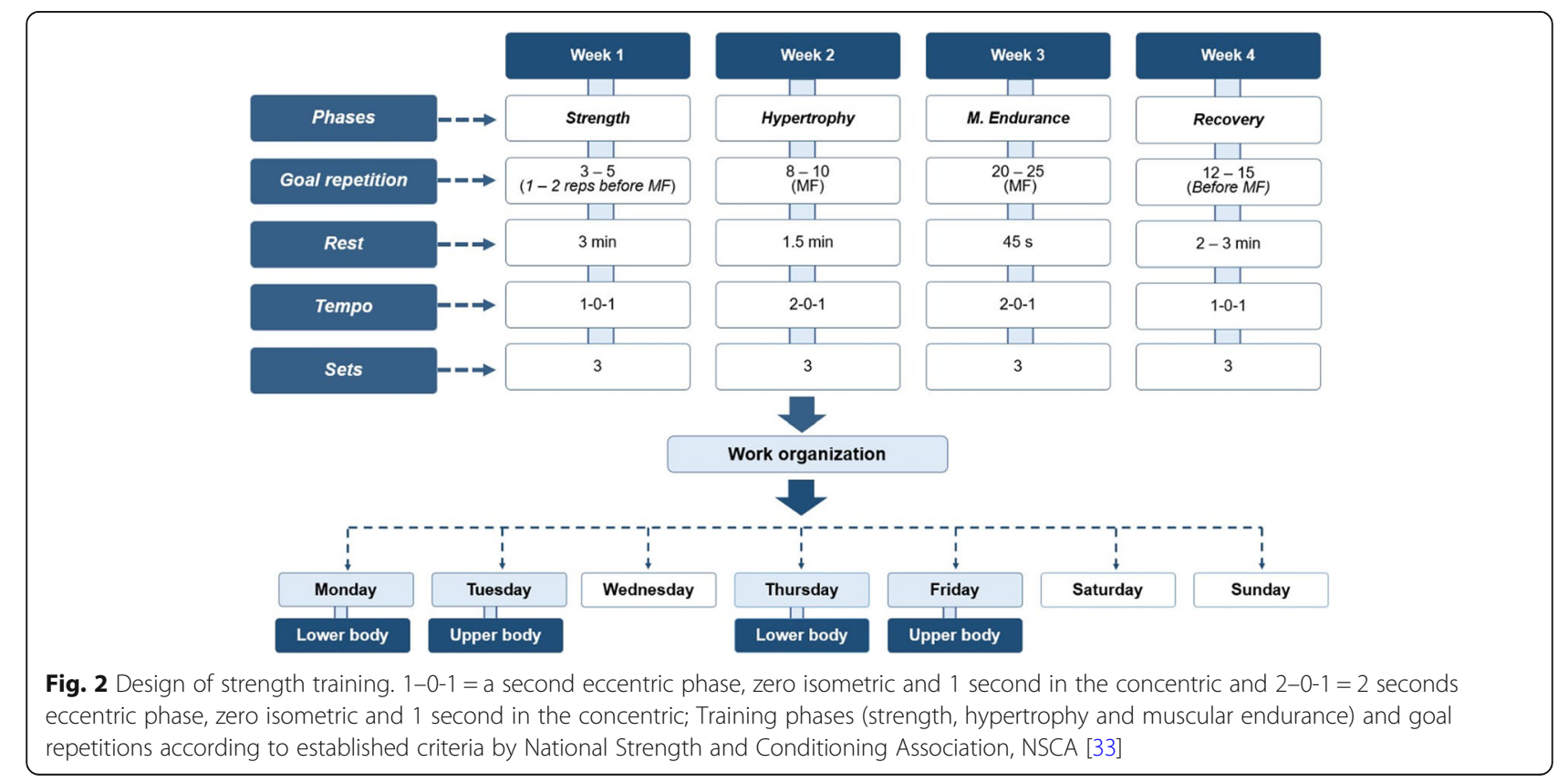


the NKD group was instructed to consume $\geq 1.7 \mathrm{~g} \cdot \mathrm{kg}^{-1}$. $\mathrm{d}^{-1}$ of protein and $1 \mathrm{~g} \cdot \mathrm{kg}^{-1} \cdot \mathrm{d}^{-1}$ of fat $(\approx 20 \%$ saturated; $\approx 48 \%$ monounsaturated; $\approx 32 \%$ polyunsaturated fat) with the remaining calories obtained from carbohydrates ( $\approx 60 \%$ starch; $\approx 25 \%$ simple; $15 \%$ fiber).

To monitor dietary intake, participants recorded their daily macronutrient intake via a smartphone app (MyFitnessPal, LLC, CA, USA), which has been validated as viable tool for energy and macronutrient assessment [38]. A sports nutritionist with experience in RT instructed participants on proper use of the app and managed dietary consumption over the course of the study.

\section{Strength levels}

For the strength tests, participants were instructed not to do any type of training during the previous $72 \mathrm{~h}$, in both pre- and post-intervention. Prior to testing, participants performed a general warm-up consisting of joint mobility and 10-12 min of low-intensity aerobic exercise on exercise bike.

The Countermovement jump (CMJ) test was performed on a jump mat (Smart Jump; Fusion Sport, Coopers Plains, Australia) after instructing participants on proper jump execution. A total of 3-5 attempts were performed for familiarization prior to obtaining measurements. Participants were instructed to initiate the move by reaching $90^{\circ}$ of knee flexion while keeping their hands at the waist and their trunk erect. Instructions emphasized that the movement should be performed without interruption from the beginning to the end of the jump. After familiarization, two jumps were recorded with a rest interval of $1 \mathrm{~min}$ between each; the highest value was computed.

One repetition maximum (RM) was evaluated in the squat (SQ) and bench press (BP) performed on a Smith machine (Gervasport, Madrid, Spain) exercises both at the beginning and at the end of the study. Participants reported to the laboratory having refrained from any exercise other than activities of daily living for at least $48 \mathrm{~h}$ before baseline testing and at least $48 \mathrm{~h}$ before testing at the conclusion of the study. In brief, participants performed a general warm-up before testing that consisted of light cardiovascular exercise lasting approximately 7 to $10 \mathrm{~min}$. A specific warm-up set of the given exercise was performed for 12 to 15 repetitions at $\sim 40 \%$ of participants' perceived 1RM followed by two to three sets of two to three repetitions at a load corresponding to approximately 60 to $80 \% 1 \mathrm{RM}$. Participants then performed sets of one repetition of increasing weight for 1RM determination. Three- to 5-min rest was provided between each successive attempt. Participants were required to reach parallel in the $1 \mathrm{RM} S \mathrm{SQ}$; confirmation of squat depth was obtained by a research assistant positioned laterally to the subject to ensure accuracy.
Successful 1RM BP was achieved if the subject displayed a five-point body contact position (head, upper back, and buttocks firmly on the bench with both feet flat on the floor) and executed full-elbow extension in the concentric phase, and the bar was required to touch the chest in the eccentric phase. 1RM SQ testing was conducted before 1RM BP with a 7-min rest period separating tests. Participants then performed as many attempts as necessary until repetition failure, using the protocol described by McGuigan [39]. Bench placement was set by marking the floor with adhesive tape, to maintain the same placement for both measurements. All testing sessions were supervised by the research team to achieve a consensus for success on each trial.

\section{Statistical analysis}

The statistical results are expressed as the mean \pm standard deviation. The comparison between the means (prevs post-test) was performed with a paired t-test or the Wilcoxon test (according to data normality), and the effect size was determined using Cohen's $d$. A repeatedmeasures general linear model (GLM) was used to evaluate the effect of intrasubject factors (Time: pre and post) and intersubject factors (i.e., the training protocol: Group) and the interaction between them (Time $\mathrm{x}$ Group). The difference in the univariate analysis of this model was established with the Greenhouse-Geisser test, also considering the partial-eta squared $\left(\eta_{\mathrm{p}}{ }^{2}\right)$ value as a measure of effect size, and the Bonferroni test was used for the post hoc analysis. Additionally, a 95\% confidence interval (CI) for the mean of the change from baseline ( $\Delta=$ pos-test - pre-test) was used to analyze significant changes in the variables, with values above or below a 95\% CI denoting significant changes. Likewise, the Mann-Whitney U test (according to data normality) was used to compare the $\Delta$ between groups. Data normality was verified with the Shapiro-Wilk test. The level of significance assumed for all tests was $P<0.05$. The statistical procedures were performed with the statistical package SPSS version 24 (SPSS Inc., Chicago, USA), and the graphs were developed using GraphPad Prism software version 7.03 (GraphPad Software, California, USA).

\section{Results}

In this study, 42 volunteers were identified, of whom eight did not meet initial inclusion criteria. Subsequently, 12 participants declined to participate after being informed about the type of training and the possibility of joining a group with controlled ketosis. Twenty-two participants were equally randomized to either the KD group or the NKD group. One subject was excluded from the KD group at Week 2 two for not showing positive ketosis strips. No statistically significant 
Table 1 Characteristics of participants at baseline

\begin{tabular}{lllll}
\hline & $\begin{array}{l}\text { KD } \\
(\boldsymbol{n}=10)\end{array}$ & $\begin{array}{l}\text { NKD } \\
(\boldsymbol{n}=11)\end{array}$ & $\begin{array}{l}\text { Total } \\
(\boldsymbol{n}=21)\end{array}$ & $\boldsymbol{p}$-value \\
\hline Age (y) & $26.8 \pm 3.9$ & $28.3 \pm 4.1$ & $27.6 \pm 4.0$ & 0.41 \\
Height (cm) & $161.6 \pm 7.4$ & $162.6 \pm 6.2$ & $162.1 \pm 6.6$ & 0.73 \\
BM (kg) & $61.9 \pm 9.8$ & $62.6 \pm 5.9$ & $62.3 \pm 7.8$ & 0.51 \\
BMI (kg·m $\left.{ }^{-2}\right)$ & $23.8 \pm 3.6$ & $23.7 \pm 2.2$ & $23.7 \pm 2.9$ & 0.96 \\
FM (kg) & $18.4 \pm 6.4$ & $18.3 \pm 4.3$ & $18.4 \pm 5.3$ & 0.98 \\
FFM (kg) & $42.8 \pm 5.4$ & $43.5 \pm 2.8$ & $43.2 \pm 4.1$ & 0.70 \\
BP (kg) & $41.5 \pm 8.4$ & $39.8 \pm 7.1$ & $40.6 \pm 7.6$ & 0.63 \\
Squat (kg) & $68.5 \pm 11.2$ & $64.5 \pm 11.3$ & $66.5 \pm 11.1$ & 0.44 \\
CMJ (cm) & $20.8 \pm 2.7$ & $22.0 \pm 4.2$ & $21.4 \pm 3.5$ & 0.45 \\
\hline
\end{tabular}

The values are expressed as average \pm standard deviation; $K D$ ketogenic diet group; NKD non-ketogenic diet group; $B M$ body mass; $B M I$ body index mass; FM fat mass; FFM fat-free mass; BP bench press; CMJ countermovement jump

differences were observed in the characteristics of the participants at baseline (Table 1).

Considering that diet planning was based on the participants' FFM $\left(\mathrm{g} \cdot \mathrm{kg}^{-1} \mathrm{FFM} \cdot \mathrm{d}^{-1}\right)$, the macronutrient distribution in relation to energy intake in the KD group resulted in $<10 \%$ for carbohydrates, $\approx 65 \%$ for fat and $\approx 26 \%$ of protein (see Table 2 for details), which allowed dietary adherence and led to a daily energy intake of $40.1 \pm 2.7 \mathrm{kcal} \cdot \mathrm{kg}-\mathrm{FFM}^{-1} \cdot \mathrm{d}^{-1}(1710.4 \pm 160.0 \mathrm{kcal} / \mathrm{d})$. On the other hand, the macronutrient distribution of the NKD group (Table 2) resulted in a daily energy intake of $45.5 \pm 1.6 \mathrm{kcal} \cdot \mathrm{kg}-\mathrm{FFM}^{-1} \cdot \mathrm{d}^{-1}(1979.6 \pm 140.0)$.

Table 2 Energy and macronutrients intake

\begin{tabular}{|c|c|c|c|}
\hline & KD & NKD & $\boldsymbol{p}$-value \\
\hline \multicolumn{4}{|l|}{ Protein } \\
\hline $\mathrm{g} \cdot \mathrm{d}^{-1}$ & $115.1 \pm 17.7$ & $97.3 \pm 7.6$ & 0.012 \\
\hline$\%$ kcal Total & $26.8 \pm 2.3$ & $19.7 \pm 1.4$ & $<0.05$ \\
\hline$g \cdot k g-F F M^{-1} \cdot d^{-1}$ & $2.7 \pm 0.3$ & $2.2 \pm 0.1$ & 0.002 \\
\hline \multicolumn{4}{|l|}{ Carbohydrates } \\
\hline$g \cdot d^{-1}$ & $38.6 \pm 4.5$ & $282.1 \pm 25.1$ & $<0.05$ \\
\hline$\%$ kcal Total & $9.1 \pm 1.3$ & $57.0 \pm 1.9$ & $<0.05$ \\
\hline $\mathrm{g} \cdot \mathrm{kg}-\mathrm{FFM}^{-1} \cdot \mathrm{d}^{-1}$ & $0.9 \pm 0.1$ & $6.5 \pm 0.4$ & $<0.05$ \\
\hline \multicolumn{4}{|l|}{ Fat } \\
\hline$g \cdot d^{-1}$ & $121.7 \pm 11.8$ & $51.3 \pm 4.6$ & $<0.05$ \\
\hline$\%$ kcal Total & $64.1 \pm 2.3$ & $23.3 \pm 1.6$ & $<0.05$ \\
\hline$g \cdot k g-F F M^{-1} \cdot d^{-1}$ & $2.9 \pm 0.2$ & $1.2 \pm 0.1$ & $<0.05$ \\
\hline \multicolumn{4}{|l|}{ Calories } \\
\hline 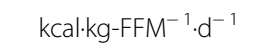 & $40.1 \pm 2.7$ & $45.5 \pm 1.6$ & $<0.05$ \\
\hline $\mathrm{kcal} \cdot \mathrm{d}^{-1}$ & $1710.4 \pm 160.0$ & $1979.6 \pm 140.0$ & 0.001 \\
\hline
\end{tabular}

The values are expressed as average \pm standard deviation; $K D$ ketogenic diet group; NKD non-ketogenic diet group; FM fat mass; FFM fat-free mass.

\section{Body composition}

\section{Body mass}

A significant post-study decrease in BM was observed with a small effect in the KD group $(P<0.01, d=-0.2)$, while the NKD group showed no significant changes $(P=0.154 ; d=0.1)$. The change with respect to baseline $(\Delta)$ in the KD group was $-2.2 \pm 1.2 \mathrm{~kg}[-3.0,-1.3 \mathrm{~kg}]$ and was considered statistically significant, while the NKD group showed a nonsignificant increase of $0.8 \pm$ $1.8 \mathrm{~kg}[-0.4,2.0 \mathrm{~kg}]$. Comparison of the $\Delta$ between the groups revealed a statistically significant difference $(P<$ 0.01 ). According to the general linear model (GLM), there was no difference considering the Time $(P=0.08$; $\left.\eta_{\mathrm{p}}{ }^{2}=0.16\right)$ or Group $\left(P=0.53 ; \eta_{\mathrm{p}}{ }^{2}=0.02\right)$ factors, but there was a difference in the Time $x$ Group interaction $\left(P<0.01 ; \eta_{\mathrm{p}}^{2}=0.52\right)$ (Table 3, Fig. 2a).

\section{Fat mass}

A significant post-study decrease in FM with a small effect was observed in the KD group $(P=0.042 ; d=-0.2)$, while the NKD group showed no significant changes $(P=0.225 ; d=0.1)$. In terms of $\Delta$, the KD group showed a decrease of $-1.1 \pm 1.5[-2.2,-0.1]$, and the NKD group showed an increase of $0.3 \pm 0.8[-0.2,0.9]$. The change was significant only for the KD group according to the CIs. Factor analysis revealed no changes considering Time $\left(P=0.19 ; \eta_{\mathrm{p}}{ }^{2}=0.09\right)$ or Group $(P=0.74$; $\left.\eta_{\mathrm{p}}{ }^{2}=0.01\right)$, but a Time $x$ Group interaction was observed $\left(P=0.01 ; \eta_{\mathrm{p}}{ }^{2}=0.30\right)$ (Table 3, Fig. 3a).

\section{Fat-free mass}

No post-study differences in FFM were observed for the KD or NKD groups $(P=0.202 ; d=-0.1$ and $P=0.074$; $d=0.2$, respectively). However, $\Delta$ showed a decrease in the KD group $(-0.7 \pm 1.7 \mathrm{~kg}[-1.9,0.5 \mathrm{~kg}])$ and an increase in the NKD group $(0.7 \pm 1.1[-0.1,1.4 \mathrm{~kg}])$, with significant differences noted between groups $(P=0.03)$. The GLM analysis revealed no differences in the Time or Group factors $\left(P=0.94 ; \eta_{\mathrm{p}}{ }^{2}=0.00\right.$ and $P=0.47$; $\eta_{\mathrm{p}}{ }^{2}=0.03$, respectively), but Time $x$ Group differences were observed $\left(P=0.04 ; \eta_{\mathrm{p}}{ }^{2}=0.2\right)$. (Table 3, Fig. 3a).

\section{Physical activity intervention Bench press}

No significant post-study increases in BP were found in the KD group $(P=0.329 ; d=0.2)$, whereas the NKD group showed significant increases of a moderate effect $(P=0.005 ; d=0.7)$. The $\Delta$ was $1.5 \pm 4.6 \mathrm{~kg}[-1.8,4.8 \mathrm{~kg}]$ for the KD group and $4.8 \pm 1.8 \mathrm{~kg}[3.6,5.9 \mathrm{~kg}$ ] for the NKD group, with significant differences shown between groups $(P=0.035)$. The GLM analysis established that there were changes considering the Time factor $(P=$ $\left.0.001 ; \eta_{\mathrm{p}}{ }^{2}=0.47\right)$ but not the Group factor $(P=0.91$; 
Table 3 Results before and after the intervention by groups

\begin{tabular}{|c|c|c|c|c|c|c|c|c|c|}
\hline & Group & $\begin{array}{l}\text { Before } \\
(X \pm S D)\end{array}$ & $\begin{array}{l}\text { After } \\
(X \pm S D)\end{array}$ & $\begin{array}{l}\mathbf{a} \\
(X \pm S D[95 \% \mathrm{Cl}])\end{array}$ & $\boldsymbol{p}$-value & $d$ & $\begin{array}{l}\text { Time } \\
P\left(n_{p}{ }^{2}\right)\end{array}$ & Group & Time $x$ Group \\
\hline \multirow[t]{2}{*}{ BM (kg) } & KD & $61.9+9.8$ & $59.7+10.1$ & $-2.2 \pm 1.2[-3.0,-1.3]^{*}$ & 0.005 & -0.2 & $0.08(0.16)$ & $0.53(0.02)$ & $<0.01(0.52)$ \\
\hline & NKD & $62.6+5.9$ & $63.4+6.5$ & $0.8 \pm 1.8[-0.4,2.0]^{*}$ & 0.154 & 0.1 & & & \\
\hline \multirow[t]{2}{*}{ FM (kg) } & KD & $18.4+6.4$ & $17.3+5.5$ & $-1.1 \pm 1.5[-2.2,-0.1]$ & 0.042 & -0.2 & $0.19(0.09)$ & $0.74(0.01)$ & $0.01(0.30)$ \\
\hline & NKD & $18.3+4.3$ & $18.7+4.5$ & $0.3 \pm 0.8[-0.2,0.9]$ & 0.225 & 0.1 & & & \\
\hline \multirow[t]{2}{*}{ FFM (kg) } & KD & $42.8+5.4$ & $42.1+6.1$ & $-0.7 \pm 1.7[-1.9,0.5]^{*}$ & 0.202 & -0.1 & $0.94(0.00)$ & $0.47(0.03)$ & $0.04(0.21)$ \\
\hline & NKD & $43.5+2.8$ & $44.2+3.4$ & $0.7 \pm 1.1[-0.1,1.4]^{*}$ & 0.074 & 0.2 & & & \\
\hline \multirow[t]{2}{*}{ BP (kg) } & $\mathrm{KD}$ & $41.5+8.4$ & $43.0+7.7$ & $1.5 \pm 4.6[-1.8,4.8]^{*}$ & 0.329 & 0.2 & $0.001(0.47)$ & $0.91(0.00)$ & $0.05(0.19)$ \\
\hline & NKD & $39.8+7.1$ & $44.6+7.4$ & $4.8 \pm 1.8[3.6,5.9]^{*}$ & $<0.01$ & 0.7 & & & \\
\hline \multirow[t]{2}{*}{ Squat (kg) } & $\mathrm{KD}$ & $68.5+11.2$ & $74.1+12.3$ & $5.6 \pm 7.6[0.1,11.0]^{*}$ & 0.045 & 0.5 & $<0.01(0.74)$ & $0.84(0.00)$ & $<0.01(0.39)$ \\
\hline & NKD & $64.5+11.3$ & $80.1+10.8$ & $15.6 \pm 5.4[11.7,19.4]^{*}$ & 0.005 & 1.4 & & & \\
\hline \multirow[t]{2}{*}{$\mathrm{CMJ}(\mathrm{cm})$} & $\mathrm{KD}$ & $20.8+2.7$ & $22.4+3.3$ & $1.7 \pm 1.9[0.3,3.1]$ & 0.022 & 0.6 & $0.00(0.56)$ & $0.48(0.03)$ & $0.46(0.03)$ \\
\hline & NKD & $22.0+4.2$ & $24.2+4.9$ & $2.2 \pm 1.7[1.1,3.4]$ & 0.001 & 0.5 & & & \\
\hline
\end{tabular}

${ }^{a}$, changes from baseline; $C l$ confidence interval; $P$, significant difference between pretest vs postest; $d$, Cohen's d; KD ketogenic diet group; NKD non-ketogenic diet group; FM fat mass; FFM fat-free mass; $B P$ bench press; $C M J$ countermovement jump; * difference $(P<0.05)$ between KD and NKD group.

$\left.\eta_{\mathrm{p}}{ }^{2}=0.00\right)$ or the Time $x$ Group interaction $(P=0.05$; $\eta_{\mathrm{p}}^{2}=0.19$ ) (Table 3, Fig. 3b).

\section{Squat}

A significant post-study increase in Squat with a moderate effect was observed in the KD group $(P=0.045 ; d=$ $0.5)$, along with a significant increase with a large effect in the NKD group $(P<0.005 ; d=1.4)$. The $\Delta$ was $5.6 \pm$ $7.6 \mathrm{~kg}[0.1,11.0 \mathrm{~kg}]$ in the KD group and $15.6 \pm 5.4 \mathrm{~kg}$ $[11.7,19.4 \mathrm{~kg}]$ in the NKD group, with significant differences between groups $(P=0.003)$. The GLM analysis of factors determined that there were differences in Time $\left(P<0.01 ; \eta_{\mathrm{p}}{ }^{2}=0.74\right)$ but not in Group $(P=0.84$; $\left.\eta_{\mathrm{p}}{ }^{2}=0.00\right)$. In the Time $x$ Group interaction, a significant difference was observed $\left(P<0.01 ; \eta_{\mathrm{p}}{ }^{2}=0.39\right)$ (Table 3, Fig. 3b).

\section{CMJ (countermovement jump)}

A significant post-study difference was found with a moderate effect in the KD and NKD groups $(P=0.022$; $d=0.6$ and $P=0.001 ; d=0.5$, respectively). The $\Delta$ was $1.7 \pm 1.9 \mathrm{~cm}[0.3,3.1 \mathrm{~cm}]$ in the KD group and $2.2 \pm 1.7$ $\mathrm{cm}[1.1,3.4 \mathrm{~cm}]$ in the NKD group, with no observed between-group $(P=0.478)$. Changes were found in the Time factor $\left(P<0.01 ; \eta_{\mathrm{p}}{ }^{2}=0.56\right)$, but not the Group factor or the Time $x$ Group interaction $\left(P=0.48 ; \eta_{\mathrm{p}}{ }^{2}=0.03\right.$ and $P=0.46 ; \eta_{\mathrm{p}}{ }^{2}=0.03$, respectively) (Table 3 , Fig. $3 \mathrm{c}$ ).

\section{Discussion}

Our study aimed to evaluate the effect of a KD on body composition and strength following an 8-week RT program in strength-trained women. In light of results obtained in men under similar conditions [17], we hypothesized that a KD combined with RT would not alter FFM or strength-related parameters in strengthtrained women; the results obtained partially support our hypothesis.

The use of reagent strips for the qualitative assessment of ketosis state was necessary in this study given the design and resource limitations. There were positive outcomes in every weekly test of the study (no data available since only dietary compliance was assessed, besides the dietary control during the intervention). With respect to FFM, we found no statistical pre- to poststudy changes in the KD group, although an absolute decrease of $0.7 \mathrm{~kg}$ was observed in this outcome. Previous research using the CrossFit $^{\oplus}$ training modality with mixed samples (men and women) generally lends support to our findings. Gregory et al. [40] found no statistical changes in DXA-derived measures of FFM following a 6-week RT program combined with a KD. However, the KD group was instructed to consume foods ad libitum with a maximum of $50 \mathrm{~g}$ of carbohydrates per day, and reported decreasing energy intake by $\sim 400 \mathrm{cal}$ across the study period. More recently, Kephart et al. [41] showed decreases in DXA-derived lower limb FFM and a decrease in vastus lateralis muscle thickness assessed by ultrasound when consuming a KD over a 12-week RT. The nutritional intervention of this study did not consider specific values of total calories or macronutrients used per $\mathrm{g} \cdot \mathrm{kg}^{-1} \cdot \mathrm{d}^{-1}$, impairing the ability to estimate whether participants were in a state of energy deficiency or surplus. Similarly, recent research on male military personnel have shown a reduction on BM (including FFM loss) in the KD group only, while the NKD group increased this parameter with a significant reduction in FM; notwithstanding, energy intake was not controlled in this study [42]. In contrast, Volek et al. [43] 


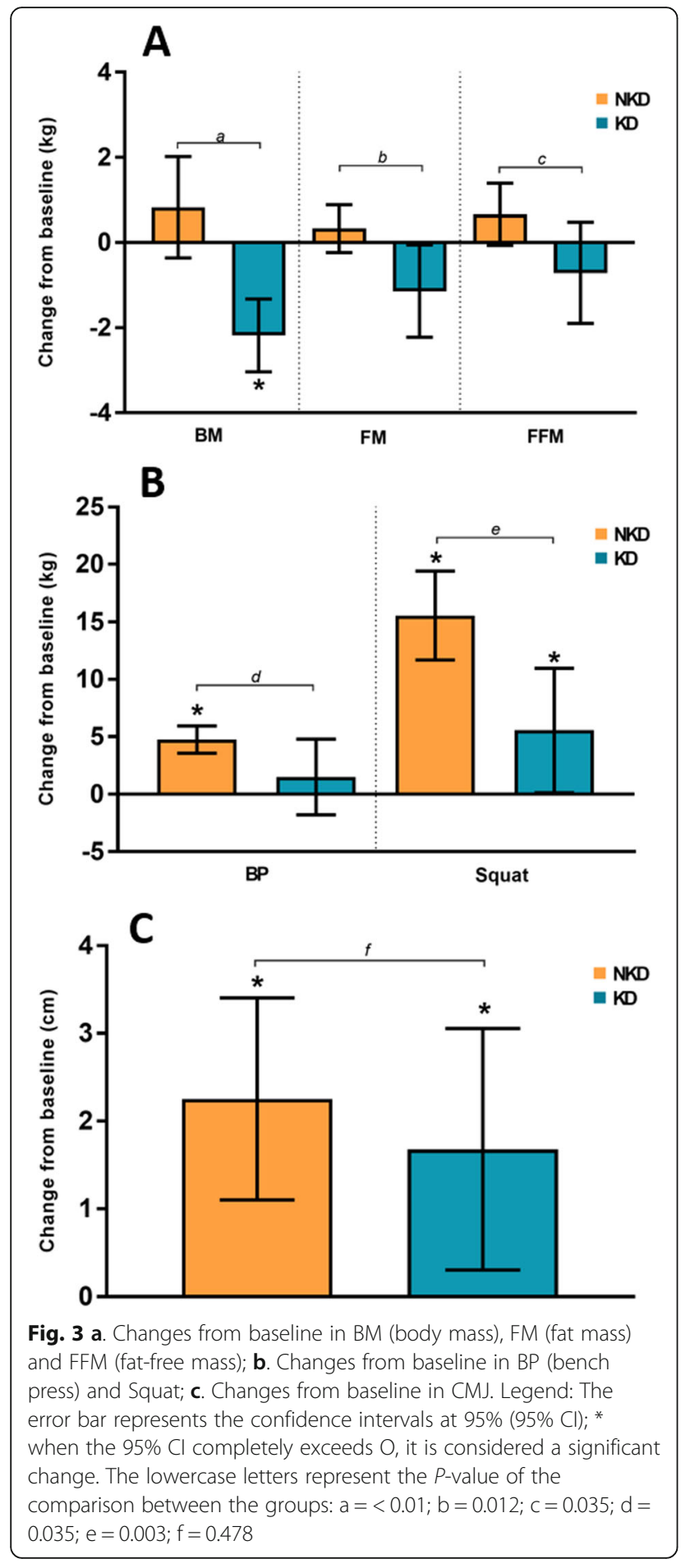

reported a statistically significant increase in FFM (1.1 $\mathrm{kg}$ ) in moderately active male participants, some of whom reported routinely performing moderate intensity RT, following a 6-week RT program. Wilson et al. [18] also reported increases in FFM following a KD combined with intensive RT in trained men. It is important to note that the evaluation of FFM by DXA includes the intracellular water, which is stored in concert with muscle glycogen in a $\sim 3: 1$ ratio [44]. Thus, implementing a carbohydrate refeed to the $\mathrm{KD}$ in the postevaluation conceivably would positively influence the final FFM results, as demonstrated by Wilson et al. [18].

Physiological differences between sexes can be problematic when attempting to extrapolate data from men to women and vice-versa. The issues are highlighted in a recent study that investigated the effects of a four-week $\mathrm{KD}$ on the utilization of fats and carbohydrates during an incremental cycling test in CrossFit ${ }^{\circ}$-trained men and men [45]. Results showed that men increased their utilization of fats to a greater extent than women during submaximal intensity exercise, suggesting some adaptations from a KD are sex-specific.

Despite our attempts to create an energy surplus, participants in KD showed signs of satiety from the fifth/ sixth week of the protocol. As shown in Table 2, reported energy consumption for participants in KD was below prescribed amounts, revealing the difficulty of eating in a caloric surplus when carbohydrate intake is severely restricted; notwithstanding, it is important to note that both groups met the daily energy intake of 40-45 $\mathrm{kcal} \cdot \mathrm{kg}-\mathrm{FFM}^{-1}$. Given that the KD group showed a mean reduction in both FM and FFM, it therefore can be concluded that these participants were in an energy deficit despite claiming adherence to the nutritional prescription. It has been previously established that KDs generate a decrease in appetite [46, 47], which can be conducive to reducing FM. However, if a KD-induced state of satiety prevents individuals from consuming the prescribed caloric intake, it could be suboptimal for increasing FFM [48, 49]. Furthermore, it should be noted the possibility that KD induces gluconeogenesis, which might reduce FFM by breaking down the endogenous proteins in a higher rate.

On the other hand, this study showed significant changes for lower-limb strength (1RM squat) in both KD and NKD groups; however, only the NKD group had significant changes on the upper-body strength (1RM BP). These results partially support the work of Wilson et al. [18] where, considering the difference in sex, the researchers found significant changes when compared to baseline values of both $1 \mathrm{RM}$ squat and $\mathrm{BP}$ in a KD and NKD group (with no differences between groups). Kephart et al. also found no negative results on the 1RM back squat when compared to a NKD group. Recently, it has been reported similar changes on anaerobic parameters related to lower and upper-limb strength and power between a KD and NKD groups [42]. In fact, our study also showed similar increases on power (CMJ) after the dietary interventions in both groups from baseline. At no time point were there any differences between conditions for peak power. 


\section{Limitations}

This study has several flaws and limitations. First, the use of urine ketone strips may be less sensitive than blood-sample methods, which represents a potential methodological limitation. Also, participants of the KD group displayed signs of reduced appetite that impaired their ability to consume the same number of daily calories in comparison to the NKD group; thus, we cannot confidently extrapolate findings to how an energy surplus affects body composition and strength adaptations in KD combined with regimented RT. However, it should be noted that at both groups met the 40-45 $\mathrm{kcal} \cdot \mathrm{kg}-\mathrm{FFM}^{-1} \cdot \mathrm{d}^{-1}$. Moreover, pre-study measures of body composition were performed when glycogen levels were high, whereas post-study measures were conceivably performed in a glycogen-depleted state for KD. Given that each gram of glycogen stores at least $\sim 3$ grams of water, this could influence data on FFM as body water is incorporated into DXA-derived measures. Finally, the relatively small sample size $(n=21)$ and short intervention time ( 8 weeks) reduce the ability to draw strong conclusions on studied outcomes.

\section{Conclusions}

Our results suggest that an 8-week is a viable option for decreasing FM and maintaining FFM when combined with regimented RT KD in strength-trained women; however, it is suboptimal for increasing FFM.

\section{Abbreviations}

BMI: Body mass index; BP: Bench press; BM: Body mass; Cl: Confidence interval; CG: Control group; CMJ: Countermovement jump; DXA: Dual-energy x-ray absorptiometry; ES: Effect size; FM: Fat mass; FFM: Fat-free mass; GLM: General lineal model; KB: Ketogenic bodies; KD: Ketogenic diet; NKD: Non-ketogenic diet; np2: Partial eta squared effect size; RM: One maximum repetition; RT: Resistance training; SQ: Squat

\section{Authors' contributions}

SV served as study coordinator. SV conceived and designed the experiments. RR and JBP served as lab coordinator and project manager for the study coordination, respectively. SV and RR assisted in data collection. SV designed and oversight the nutritional protocols and training. JLP analyzed the data. $S V, J L P, B J S, R B K, J B P$, and DAB assisted in analysis, and manuscript review. SV, JLP, BJS and JBP wrote the paper. RBK, BJS, DAB, JLP and JBP assisted in the statistics advice, discussion analysis, and manuscript preparation. All authors read and approved the final manuscript.

\section{Funding}

Supported by University of Málaga (Campus of International Excellence Andalucía Tech)

\section{Availability of data and materials}

The datasets used and analyzed during the current study are available from the corresponding author on reasonable request.

\section{Ethics approval and consent to participate}

Participation in the study was voluntary, with written consent being obtained from each subject before the initiation of data collection. This study was conducted after review and approval by the Ethics Committee of the University of Málaga (Málaga, Spain). Committee's reference number: 382019-H.

\section{Consent for publication}

Not applicable.

\section{Competing interests}

The authors declare that they have no competing interests and do not eat a ketogenic diet.

\section{Author details}

${ }^{1}$ Human Kinetics and Body Composition Laboratory, University of Málaga, Bulevar Louis Pasteur, 25, 29010 Málaga, Spain. EADE-University of Wales Trinity Saint David, Málaga, Spain. ${ }^{3}$ Research Group in Physical Activity, Sports and Health Sciences (GICAFS), Universidad de Córdoba, Montería, Colombia. ${ }^{4}$ Research Division, DBSS INTERNATIONAL SAS, Bogotá, Colombia. ${ }^{5}$ Exercise \& Sport Nutrition Lab, Human Clinical Research Facility, Texas A\&M University, College Station, TX, USA. ${ }^{6}$ Department of Health Sciences, CUNY Lehman College, New York, USA.

Received: 26 November 2019 Accepted: 27 March 2020

Published online: 10 April 2020

\section{References}

1. Zinn C, Wood M, Williden M, Chatterton S, Maunder E. Ketogenic diet benefits body composition and well-being but not performance in a pilot case study of New Zealand endurance athletes. J Int Soc Sports Nutr. 2017; 14:22.

2. Aragon AA, Schoenfeld BJ, Wildman R, Kleiner S, VanDusseldorp T, Taylor L, Earnest CP, Arciero PJ, Wilborn C, Kalman DS, et al. International society of sports nutrition position stand: diets and body composition. J Int Soc Sports Nutr. 2017;14:16

3. Paoli A. Ketogenic diet for obesity: friend or foe? Int J Environ Res Public Health. 2014:11:2092-107.

4. Bueno NB, de Melo IS, de Oliveira SL, da Rocha AT. Very-low-carbohydrate ketogenic diet v. low-fat diet for long-term weight loss: a meta-analysis of randomised controlled trials. Br J Nutr. 2013;110:1178-87.

5. Dashti HM, Mathew TC, Hussein T, Asfar SK, Behbahani A, Khoursheed MA, Al-Sayer HM, Bo-Abbas YY, Al-Zaid NS. Long-term effects of a ketogenic diet in obese patients. Exp Clin Cardiol. 2004:9:200-5.

6. Lima PA, Sampaio LP, Damasceno NR. Neurobiochemical mechanisms of a ketogenic diet in refractory epilepsy. Clinics (Sao Paulo). 2014;69:699-705.

7. Paoli A, Bianco A, Damiani E, Bosco G. Ketogenic diet in neuromuscular and neurodegenerative diseases. Biomed Res Int. 2014;2014:474296.

8. Winesett SP, Bessone SK, Kossoff EH. The ketogenic diet in pharmacoresistant childhood epilepsy. Expert Rev Neurother. 2015;15:621-8.

9. Armeno M, Caraballo R, Vaccarezza M, Alberti MJ, Rios V, Galicchio S, de Grandis ES, Mestre G, Escobal N, Matarrese P, et al. national consensus on the ketogenic diet. Rev Neurol. 2014;59:213-23.

10. Allen BG, Bhatia SK, Anderson CM, Eichenberger-Gilmore JM, Sibenaller ZA, Mapuskar KA, Schoenfeld JD, Buatti JM, Spitz DR, Fath MA. Ketogenic diets as an adjuvant cancer therapy: history and potential mechanism. Redox Biol. 2014:2:963-70.

11. Vidali S, Aminzadeh S, Lambert B, Rutherford T, Sperl W, Kofler B, Feichtinger RG. Mitochondria: the ketogenic diet--a metabolism-based therapy. Int J Biochem Cell Biol. 2015;63:55-9.

12. Woolf EC, Scheck AC. The ketogenic diet for the treatment of malignant glioma. J Lipid Res. 2015;56:5-10.

13. McSwiney FT, Doyle L, Plews DJ, Zinn C. Impact of ketogenic diet on athletes: current insights. Open Access J Sports Med. 2019;10:171-83.

14. Burke LM. Re-examining high-fat diets for sports performance: did we call the 'Nail in the Coffin' too soon? Sports Med. 2015:45(Suppl 1):S33-49.

15. McKay AKA, Peeling P, Pyne DB, Welvaert M, Tee N, Leckey JJ, Sharma AP, Ross MLR, Garvican-Lewis LA, Swinkels DW, et al. Chronic adherence to a ketogenic diet modifies Iron metabolism in elite athletes. Med Sci Sports Exerc. 2019;51:548-55

16. Heikura IA, Burke LM, Hawley JA, Ross ML, Garvican-Lewis L, Sharma AP, McKay AKA, Leckey JJ, Welvaert M, McCall L, Ackerman KE. A Short-term ketogenic diet impairs markers of bone health in response to exercise. Front Endocrinol. 2020;10

17. Vargas S, Romance R, Petro JL, Bonilla DA, Galancho I, Espinar S, Kreider RB, Benitez-Porres J. Efficacy of ketogenic diet on body composition during resistance training in trained men: a randomized controlled trial. J Int Soc Sports Nutr. 2018;15:31. 
18. Wilson JM, Lowery RP, Roberts MD, Sharp MH, Joy JM, Shields KA, Partl J, Volek JS, D'Agostino D. The effects of ketogenic dieting on body composition, Strength, Power, and Hormonal Profiles in Resistance Training Males. J Strength Cond Res. 2017

19. Volek JS, Sharman MJ, Gomez AL, DiPasquale C, Roti M, Pumerantz A, Kraemer WJ. Comparison of a very low-carbohydrate and low-fat diet on fasting lipids, LDL subclasses, insulin resistance, and postprandial lipemic responses in overweight women. J Am Coll Nutr. 2004;23:177-84.

20. Dallongeville J, Gruson E, Dallinga-Thie G, Pigeyre M, Gomila S, Romon M. Effect of weight loss on the postprandial response to high-fat and highcarbohydrate meals in obese women. Eur J Clin Nutr. 2007;61:711-8.

21. Jabekk PT, Moe IA, Meen HD, Tomten SE, Høstmark AT. Resistance training in overweight women on a ketogenic diet conserved lean body mass while reducing body fat. Nutr Metab. 2010;7:17.

22. Gregory RM, Hamdan H, Torisky D, Akers J. A low-carbohydrate ketogenic diet combined with 6-weeks of crossfit training improves body composition and performance. Int J Sports Exerc Med. 2017:3:1-10.

23. Baetge C, Earnest CP, Lockard B, Coletta AM, Galvan E, Rasmussen C, Levers K, Simbo SY, Jung YP, Koozehchian M, et al. Efficacy of a randomized trial examining commercial weight loss programs and exercise on metabolic syndrome in overweight and obese women. Appl Physiol Nutr Metab. 2017; 42:216-27.

24. Coletta AM, Sanchez B, O'Connor A, Dalton R, Springer S, Koozehchian MS, Murano PS, Woodman CR, Rasmussen C, Kreider RB. Alignment of diet prescription to genotype does not promote greater weight loss success in women with obesity participating in an exercise and weight loss program. Obes Sci Pract. 2018:4:554-74.

25. Kerksick C, Thomas A, Campbell B, Taylor L, Wilborn C, Marcello B, Roberts M, Pfau E, Grimstvedt M, Opusunju J, et al. Effects of a popular exercise and weight loss program on weight loss, body composition, energy expenditure and health in obese women. Nutr Metab (Lond). 2009;6:23.

26. Kerksick CM, Roberts MD, Campbell Bl, Galbreath MM, Taylor LW, Wilborn CD, Lee A, Dove J, Bunn JW, Rasmussen CJ, Kreider RB. Differential impact of calcium and vitamin $\mathrm{D}$ on body composition changes in post-menopausal women following a restricted energy diet and exercise program. Nutrients. 2020:12.

27. Kerksick CM, Wismann-Bunn J, Fogt D, Thomas AR, Taylor L, Campbell BI, Wilborn CD, Harvey T, Roberts MD, La Bounty P, et al. Changes in weight loss, body composition and cardiovascular disease risk after altering macronutrient distributions during a regular exercise program in obese women. Nutr J. 2010;9:59.

28. Lockard B, Earnest CP, Oliver J, Goodenough C, Rasmussen C, Greenwood M, Kreider RB. Retrospective analysis of protein- and carbohydrate-focused diets combined with exercise on metabolic syndrome prevalence in overweight and obese women. Metab Syndr Relat Disord. 2016;14:228-37.

29. World Medical A. World medical association declaration of Helsinki: ethical principles for medical research involving human subjects. JAMA. 2013;310: 2191-4

30. Sung E, Han A, Hinrichs T, Vorgerd M, Manchado C, Platen P. Effects of follicular versus luteal phase-based strength training in young women. SpringerPlus. 2014;3:668

31. Rosenfeld R, Livne D, Nevo O, Dayan L, Milloul V, Lavi S, Jacob G. Hormonal and volume dysregulation in women with premenstrual syndrome. Hypertension. 2008;51:1225-30.

32. Stachenfeld NS. Sex hormone effects on body fluid regulation. Exerc Sport Sci Rev. 2008;36:152-9.

33. Sheppard J, Triplett NT. Program design for resistance training. In: Haff G, Triplett N, editors. Essentials of Strength Training and Conditioning. Champaign: Human Kinetics; 2016. p. 457-8.

34. Loucks AB. Energy availability, not body fatness, regulates reproductive function in women. Exerc Sport Sci Rev. 2003;31:144-8.

35. Reed JL, De Souza MJ, Mallinson RJ, Scheid JL, Williams NI. Energy availability discriminates clinical menstrual status in exercising women. J Int Soc Sports Nutr. 2015;12:11.

36. Wooding DJ, Packer JE, Kato H, West DWD, Courtney-Martin G, Pencharz PB, Moore DR. Increased protein requirements in female athletes after variableintensity exercise. Med Sci Sports Exerc. 2017;49:2297-304.

37. Urbain P, Bertz H. Monitoring for compliance with a ketogenic diet: what is the best time of day to test for urinary ketosis? Nutr Metab. 2016;13:77.
38. Teixeira V, Voci SM, Mendes-Netto RS, da Silva DG. The relative validity of a food record using the smartphone application MyFitnessPal. Nutr Diet. 2018;75:219-25.

39. McGuigan M. Administration, scoring, and interpretation of selected tests. In: Haff G, Triplett T, editors. Essentials of Strength Training and Conditioning. Champaign: Human Kinetics; 2016. p. 265-6.

40. Gregory R. A low-carbohydrate ketogenic diet combined with 6-weeks of Crossfit training improves body composition and performance. Int J Sports Exercise Med. 2017;3:1-10

41. Kephart WC, Pledge CD, Roberson PA, Mumford PW, Romero MA, Mobley CB, Martin JS, Young KC, Lowery RP, Wilson JM, et al. The three-month effects of a ketogenic diet on body composition, blood parameters, and performance metrics in CrossFit trainees: a pilot study. Sports (Basel). 2018;6: $1-11$.

42. LaFountain RA, Miller VJ, Barnhart EC, Hyde PN, Crabtree CD, McSwiney FT, Beeler MK, Buga A, Sapper TN, Short JA, et al. Extended ketogenic diet and physical training intervention in military personnel. Mil Med. 2019;184(9-10): e538-e547. https://doi.org/10.1093/milmed/usz046.

43. Volek JS, Sharman MJ, Love DM, Avery NG, Gomez AL, Scheett TP, Kraemer WJ. Body composition and hormonal responses to a carbohydrate-restricted diet. Metabolism. 2002;51:864-70.

44. Fernandez-Elias VE, Ortega JF, Nelson RK, Mora-Rodriguez R. Relationship between muscle water and glycogen recovery after prolonged exercise in the heat in humans. Eur J Appl Physiol. 2015;115:1919-26.

45. Durkalec-Michalski K, Nowaczyk PM, Siedzik K. Effect of a four-week ketogenic diet on exercise metabolism in CrossFit-trained athletes. J Int Soc Sports Nutr. 2019;16:16.

46. Boden G, Sargrad K, Homko C, Mozzoli M, Stein TP. Effect of a lowcarbohydrate diet on appetite, blood glucose levels, and insulin resistance in obese patients with type 2 diabetes. Ann Intern Med. 2005;142:403-11.

47. McClernon FJ, Yancy WS Jr, Eberstein JA, Atkins RC, Westman EC. The effects of a low-carbohydrate ketogenic diet and a low-fat diet on mood, hunger, and other self-reported symptoms. Obesity (Silver Spring). 2007;15:182-7.

48. Margolis LM, Rivas DA, Berrone M, Ezzyat Y, Young AJ, McClung JP, Fielding RA, Pasiakos SM. Prolonged calorie restriction downregulates skeletal muscle mTORC1 signaling independent of dietary protein intake and associated microRNA expression. Front Physiol. 2016:7:445.

49. Pasiakos SM, Vislocky LM, Carbone JW, Altieri N, Konopelski K, Freake HC, Anderson JM, Ferrando AA, Wolfe RR, Rodriguez NR. Acute energy deprivation affects skeletal muscle protein synthesis and associated intracellular signaling proteins in physically active adults. J Nutr. 2010;140: 745-51.

\section{Publisher's Note}

Springer Nature remains neutral with regard to jurisdictional claims in published maps and institutional affiliations.
Ready to submit your research? Choose BMC and benefit from:

- fast, convenient online submission

- thorough peer review by experienced researchers in your field

- rapid publication on acceptance

- support for research data, including large and complex data types

- gold Open Access which fosters wider collaboration and increased citations

- maximum visibility for your research: over $100 \mathrm{M}$ website views per year

At BMC, research is always in progress.

Learn more biomedcentral.com/submissions 